that reported an objective cure rate of $76 \%$, considerably lower than the $90 \%$ reported long-term cure rate for the standard TVT. ${ }^{5}$ The other widely marketed device, the Mini-Arc, also has inconsistent outcomes with some studies showing cure rates as low as $62 \%{ }^{6}$

Gynaecologists and urologists need to be aware of these poorer outcomes, for the TVT-Secur and the Mini-Arc in particular. While mini-slings hold future promise, present products are inferior to standard sling operations and their use should be discouraged.

\author{
John Lazarus \\ Division of Urology \\ Groote Schuur Hospital and University of Cape Town \\ j.lazarus@uct.ac.za
}

\section{Stephen Jeffery}

Department of Obstetrics and Gynaecology

Groote Schuur Hospital and University of Cape Town

\section{Lisa Kaestner}

Division of Urology

Groote Schuur Hospital and University of Cape Town

\footnotetext{
1. Luber KM. The definition, prevalence, and risk factors for stress urinary incontinence. Rev Urol 2004;6(suppl 3):S3-S9.

2. Ulmsten U, Petros P. Intravaginal slingplasty (IVS): an ambulatory surgical procedure for treatment of

female urinary incontinence. Scand J Urol Nephrol 1995;29:75-82. 3. Delorme E. [Transobturator urethral suspension: mini-invasive p
urinary incontinence in women]. Prog Urol 2001;11(6):1306-1313.

4. Fong EDM, Nitti VW. Mid-urethral synthetic slings for female stress urinary incontinence. BJU Int Fong EDM, Nitti

2010;106:596-608.
5. Walsh CA. TVT-Secur mini-sling for stress urinary incontinence: a review of outcomes at 12 months. 5. Walsh CA. TVT-Secur mini-s
BJU Int 2011;108(5):652-627.

6. Deole N, Kaufmann A, Arunkalaivanan A. Evaluation of safety and efficacy of single-incision midurethral short tape procedure (MiniArc ${ }^{\text {"I }}$ tape) for stress urinary incontinence under local anaesthesia. Int Urogynecol J 2011;22(3):335-339.
}

\section{Management guidelines for common kidney disorders relevant to South Africa}

To the Editor: World Kidney Day (WKD), an annual event, is celebrated on 8 March 2012. As a project for WKD, the National Kidney Foundation of South Africa (NKFSA) has arranged for a group of experienced senior nephrologists from around the country to contribute to a guideline booklet presenting the diagnosis and state-of-the-art management of renal disorders. Its main aim is to educate and update general practitioners, but it should also be useful for under- and postgraduate students, urologists and specialist physicians.

The guideline is being edited and will be sent to the South African Renal Society for their endorsement. We aim to publish the guideline as a supplement to the South African Medical Journal. We thank the contributors to and supporters of the project, and the National Lotteries Distribution Trust Fund for financial support towards the initial draft copy of the guideline.

\section{A M Meyers}

Chairman, National Kidney Foundation of South Africa

\section{Fanie du Toit}

Administrator, NKFSA

$n k f s a @ m w e b . c o . z a$

\section{Health professionals should be speaking out about the victimisation of doctors in Bahrain}

To the Editor: Doctors in Bahrain who treated people wounded during and after demonstrations have been arrested, tried by a military court and given sentences of up to 15 years' imprisonment. A report by the Physicians for Human Rights ${ }^{1}$ recounts the result of an on-the-spot inquiry as follows: 'Our investigators spoke to eyewitnesses of abducted physicians, some of whom were ripped from their homes in the middle of the night by masked security forces ... [the report] documents other violations of medical neutrality, including the beating, abuse and threatening of Shia physicians at Salmaniya Hospital; government security forces stealing ambulances and posing as medics; the militarisation of hospitals and clinics, thus obstructing medical care; and rampant fear that prevents patients from seeking urgent medical treatment.' Most of the doctors are women, and there have been reports of torture, including electrocution and threats of rape while in detention. ${ }^{2}$

These accounts are shocking and remind South Africans of a sorry history where human rights abuses at the hands of security forces were allowed to go unchecked and where the health sector was drawn willingly and unwillingly into violations of the rights of patients and professionals. ${ }^{3}$ Not surprisingly, there has been sustained outcry from the medical profession in other parts of the world..$^{4-7}$ Following the exposé by Physicians for Human Rights, and pressure by the World Health Organization and the World Medical Association, it was announced by a civilian court that some charges against 20 health professionals would be dropped and that a new trial would begin to assess the allegations. ${ }^{8}$

We ask why there has been so little outcry in South Africa, a country whose history should make it acutely aware of the consequences of the political abuse of doctors. The South African Medical Association released a Medigram reporting the resolution of the WMA, ${ }^{9}$ but has not taken any proactive steps to champion the cause of the persecuted doctors. Why has SAMA not been more active? Why have members of the medical profession not seen it as their ethical obligation to take action in solidarity with colleagues, if only to press our government, a member of the UN Security Council, to take diplomatic action? One of the consistent findings of research into complicity of health professionals in human rights abuses ${ }^{3,10,11}$ has been the effect of isolation and a failure to stand up for colleagues under threat, a finding echoed in the conclusions of the Truth and Reconciliation Commission., ${ }^{3,11}$

It appears that since the late 1970s we have not learnt sufficiently the importance of health professionals speaking truth to power. One of us (SS) wrote to the President of SAMA, urging SAMA to take action, to which there was not even an acknowledgement. South Africans deserve better.

\section{Stuart Saunders \\ Emeritus Professor}

University of Cape Town

\section{Leslie London}

School of Public Health and Family Medicine

University of Cape Town

leslie.london@uct.ac.za 1. Physicians for Human Rights. Do no harm: A call for Bahrain to end systematic attacks on doctors
and patients. Physicians for Human Rights, Cambridge. April 2011. https://s3.amazonaws.com/PHR.../ bahrain-22April 4-45pm.pdf (accessed 12 January 2012). 